\title{
¿Es la asistencia sexual un derecho?
}

\author{
Is sexual assistance a right?
}

\section{Resumen:}

En este trabajo voy a reflexionar sobre la cuestión de la asistencia sexual y su posible configuración como derecho. La contestación a la pregunta sobre si la asistencia sexual es un derecho puede variar dependiendo del marco en el que nos desenvolvamos. Así, podemos estar hablando desde un marco estrictamente jurídico, desde un marco ético, o desde un marco a caballo entre ambos como es el de los derechos humanos. A partir de aquí, la pregunta sobre si la asistencia sexual es un derecho dependerá de la pregunta sobre qué es la asistencia sexual. La justificación de la asistencia sexual en relación con personas que no pueden realizar actividad sexual sobre su propio cuerpo puede encontrar una justificación ética de la mano de la teoría de las necesidades o de la mano de las Actividades Básicas de la Vida Diaria, e igualmente puede formar parte de los derechos sexuales o del derecho a elegir una forma de vida.

\section{Palabras clave}

Discapacidad, derechos sexuales, asistencia, apoyos.

\section{Abstract}

In this paper I will reflect on sexual assistance, and I will draw your attention on the possibility of shaping sexual assistance as a right. The question of whether sexual assistance is a right can have different answers depending on the framework we are in. We could fall within a purely legal framework, an ethical framework, or a combined framework such as a human rights context. From this point onwards, the question of whether sexual assistance is a right shall depend on the answer to the question regarding the nature of sexual assistance. Sexual assistance for people who cannot perform sexual activities on their own body can be ethically justified by the theory of needs or by the notion of Instrumental Activities of Daily Living. It can also fall within sexual rights or within the right to choose a way of life.

\section{Keywords}

Disability, sexual rights, assistance, supports.

I. Este trabajo se ha realizado en el marco de los proyectos 'Madrid sin Barreras: discapacidad e inclusión social' (S2OI 5/HUM-3330) y 'Diseño, accesibilidad y ajustes. El eje de los derechos de las personas con discapacidad' (DER 20I6-75I64-P). Una primera versión la compartí en las Jornadas sobre Diversidad Funcional y Asistencia Sexual, celebradas en la Universidad Carlos III de Madrid, en mayo de 2017. Agradezco a los asistentes sus observaciones. También agradezco a Pablo A. Cantero Garlito sus observaciones sobre las Actividades Básicas de la Vida Diaria.

\section{Rafael de Asís}

<rafael.asis@uczm.es>

Instituto de Derechos Humanos

Bartolomé de las Casas.

Universidad Carlos III de Madrid
Para citar:

De Asís, R. (20I7): “¿Es la asistencia sexual un derecho?”. Revista Española de Discapacidad, 5 (2): 7-I8.

Doi: <https://doi.org/IO.5569/23405 I04.05.02.0I >

Fecha de recepción: 1 3-07-20I7 Fecha de aceptación: 06-II-20I7 


\section{Introducción}

La reflexión sobre la asistencia sexual, su significado y alcance, en el marco de los derechos de las personas con discapacidad, ha adquirido una mayor relevancia en los últimos años. A ello han contribuido diversos factores, tales como la asunción de la necesidad de utilizar un enfoque de derechos humanos cuando hablamos de discapacidad, la realización de seminarios y trabajos doctrinales sobre esta materia, o la aparición de organizaciones que proporcionan estos servicios.

No es un tema sencillo ya que se enfrenta a cuestiones aún no resueltas desde un punto de vista teórico general, con posiciones enfrentadas y con presencia de muchos estereotipos, sobre todo en lo que se refiere a las personas con discapacidad.

No cabe duda que la reflexión sobre actividad sexual y derechos sexuales en el ámbito de la discapacidad ha estado condicionada por una serie de presupuestos que hay que combatir desde el principio. En un trabajo publicado no hace mucho, me refería a tres pasos que debíamos dar en el tratamiento de los derechos de las personas con discapacidad, siendo uno de ellos el de la normalidad.

La cuestión de la normalidad consiste en luchar contra los estereotipos presentes en ese tema y que parten, en muchos casos, de la consideración de las personas con discapacidad como seres asexuales o, en todo caso, dependientes sexualmente; o con la consideración de que sólo deben relacionarse con otras personas con discapacidad, o con la idea de que las personas con discapacidad intelectual "manifiestan un impulso sexual exacerbado, o que no controlan adecuadamente su expresión sexual” (Arnau, 20I4: 9).

En este trabajo voy a reflexionar sobre la cuestión de la asistencia sexual y su posible configuración como derecho. Vaya por delante que lo haré en el marco de la teoría de los derechos humanos (Barranco, 2016) y adoptando, como no podría ser de otra manera, un enfoque de la discapacidad basado en los derechos humanos (Palacios, 2008: I03 y ss.).

\section{El sentido de la pregunta}

La contestación a la pregunta sobre si la asistencia sexual es un derecho puede variar dependiendo del marco en el que nos desenvolvamos. Así, podemos estar hablando desde un marco estrictamente jurídico, desde un marco ético, o desde un marco a caballo entre ambos como es el de los derechos humanos.

Si adoptamos un punto de vista jurídico, la contestación exige aclarar qué es un derecho y cuándo estamos en presencia de un derecho. Se trata de dos cuestiones que no admiten una única respuesta, ya que dependen de escuelas y doctrinas.

En efecto, la cuestión sobre qué es un derecho se ha respondido de forma distinta a lo largo de la historia del Derecho. En este punto es muy conocida la pugna entre dos grandes teorías representadas por dos reconocidos juristas, la teoría del interés (Ihering) y la teoría de la voluntad (Savigny), pero también lo es la existencia de otras visiones (incluso algunas de ellas negadoras de su existencia).

A los efectos de este trabajo, podemos pensar en un derecho en términos de voluntad o en términos de interés (subjetivo u objetivo). Pero, además, podemos entender el derecho como una situación. Precisamente este es el punto de otro reconocido jurista muy estudiado cuando hablamos de derecho subjetivo: W.N. Hohfeld.

Hohfeld estudió el uso de ese término en el campo del Derecho y señaló cuatro posibles significados (Hohfeld, I968). Así, según este autor, el término derecho se utilizaba bien como pretensión, como libertad, como potestad y como inmunidad. Para comprender su 
significado, Hohfeld estableció una relación de opuestos (lo contrario a estar en una situación de derecho para la propia persona) y de correlativos (situación en la que se encuentra otra persona cuando estoy en una situación de derecho).

De esta forma el opuesto a pretensión es el no-derecho y el correlativo es el deber; el opuesto a la libertad es el deber y el correlativo el no-derecho; el opuesto a la potestad es la incompetencia y el correlativo la sujeción; y el opuesto a la inmunidad es la sujeción y el correlativo la incompetencia.

De lo anterior me interesa recalcar que detrás de un derecho hay una voluntad o un interés, que se manifiesta bien en términos de pretensión, libertad, potestad o inmunidad, y que implica que hay alguien que está en una situación susceptible de identificar en términos de obligación.

Ahora bien, la conclusión anterior es insuficiente porque la existencia de un derecho requiere además de un reconocimiento jurídico, es decir, la situación que está detrás del derecho está reconocida jurídicamente o también, el interés o la voluntad tienen que tener un reconocimiento jurídico.

$\mathrm{Y}$, ¿cómo se obtiene ese reconocimiento jurídico? Pues básicamente ese reconocimiento se obtiene a través de una norma que, o bien directamente reconoce ese derecho, o bien otorga competencia para establecer relaciones jurídicas desde las que se configuran derechos y obligaciones. En ambos casos, la existencia de la norma o la validez de la relación jurídica dependerá de su conformidad con el resto de normas y, finalmente, con el respeto a los criterios de validez jurídica representados, en los sistemas constitucionales, por los derechos humanos.

A partir de aquí, la pregunta sobre si la asistencia sexual es un derecho dependerá de la pregunta sobre qué es la asistencia sexual. Si nos planteamos ahora la pregunta desde un punto de vista ético, estaremos pensando en la asistencia sexual como un derecho moral, término polémico en la Filosofía jurídica (Nino, I990: 3 I I y ss.). Pero, ¿qué es un derecho moral y cuándo estamos en presencia de un derecho moral?

Pues bien, al igual que ocurría en el campo jurídico, no existe una única respuesta a esta cuestión. Los derechos morales se han entendido como facultades, potestades, libertades, pretensiones, intereses, voluntades, inmunidades, capacidades, posibilidades, necesidades... Como puede observarse, en este punto no hay grandes diferencias entre la construcción jurídica y la ética.

Más allá de lo anterior, lo relevante en la construcción de los derechos morales es, de forma parecida también a lo que ocurría en el ámbito del Derecho, la del reconocimiento ético de esa pretensión. Y ese reconocimiento aparece como razón, esto es, se tiene un derecho moral cuando hay una razón moral que sirve de justificación. En este sentido, la existencia de un derecho moral dependerá de la fuerza de la razón que pretende servir de justificación.

A partir de aquí, la pregunta sobre si la asistencia sexual es un derecho moral dependerá de la pregunta sobre qué es la asistencia sexual.

Por último, podemos plantearnos esta cuestión desde un punto de vista de los derechos humanos: ¿es la asistencia sexual un derecho humano? Pues bien, al igual que en los dos casos anteriores, contestar a esta pregunta requiere saber qué es un derecho humano; pregunta que, de igual manera, no posee una única respuesta. No obstante, conviene señalar que, a diferencia de los dos casos anteriores, contamos con un catálogo de derechos humanos presentes en declaraciones internacionales y en constituciones, con lo que un camino a seguir para contestar a esta pregunta puede ser el de buscar el reconocimiento de la asistencia sexual en alguno de estos textos.

Pues bien, si examinamos derechos humanos contenidos en declaraciones, convenciones y constituciones, veremos como no encontramos ningún derecho a la asistencia sexual. Otra cosa 
es que podamos argumentar sobre su existencia a través de otros derechos o de valores propios del discurso de los derechos humanos. Pero este camino nos obliga a plantearnos, ahora sí, qué son los derechos humanos.

Aunque existen diferentes formas de entender los derechos humanos (Rodríguez Toubes, I995: 20 y ss.), es posible encontrar algunos rasgos presentes prácticamente en cualquiera de sus concepciones y que coinciden con la dimensión jurídica y ética de la idea de derecho (De Asís, 200I: 6 y ss.). Así, los derechos humanos son exigencias, necesidades, pretensiones..., que pueden manifestarse en cualquiera de las situaciones descritas por Hohfeld, que poseen por lo general un respaldo normativo, y que cuentan con razones éticas para su satisfacción. Lo que sirve para singularizar a los derechos humanos es que, en la situación correlativa de deber siempre va a estar, además de otros, el Estado (ya sea como garante o como promotor), y que la argumentación ética que proporciona razones para su justificación, está relacionada con el desarrollo de una vida humana digna.

Y así, de nuevo en este punto, resulta esencial esclarecer el significado de la asistencia sexual para ver, ahora, si tiene relación con la vida humana digna.

De lo visto hasta aquí, y a expensas de aclarar el significado de la asistencia sexual, la pregunta sobre si constituye o no un derecho, depende, en un sentido jurídico, de la existencia de una norma jurídica válida; en su sentido ético, de la existencia de una razón moral; en un sentido de derecho humano de una norma, pero sobre todo de la existencia de una obligación del Estado y de una razón vinculada a la vida humana digna.

\section{3. ¿Qué es la asistencia sexual?}

Al igual que nos ocurría con la idea de derecho, no existe una única visión de la asistencia sexual. En un sentido primario, con este término se está haciendo alusión a un apoyo o ayuda para la realización de una actividad sexual. En este sentido, la asistencia implica intervención de un tercero ${ }^{2}$ siendo este un aspecto que condiciona y concreta la visión sobre la actividad sexual. Así, en un sentido básico, podemos diferenciar tres tipos de actividad sexual. Por un lado, la actividad de una persona sobre su propio cuerpo, por otro, la actividad consistente en una relación sexual física entre dos personas, y, por último, la actividad consistente en una relación sexual entre dos personas sin contacto físico.

En el ámbito de la discapacidad, el término asistencia se suele utilizar para referirse a la asistencia personal. La asistencia personal consiste en una actividad por la que una persona ayuda a otra persona a realizar diferentes actividades e incluso llega a realizarlas por esta persona. Así, un asistente personal es “quien realiza o ayudar a realizar las tareas de la vida diaria a otra persona que por su situación, bien sea por una diversidad funcional o por otros motivos, no puede ejecutarla por sí misma” (Arnau, S., Romañach, J. y Rodríguez-Picavea, A., 2007: 5$)^{3}$.

Como es sabido, la cuestión de la asistencia forma parte del discurso de los derechos de las personas con discapacidad, siendo una parte esencial de lo que en otros lugares he denominado como eje de la accesibilidad, compuesto por el diseño universal (que funciona como un principio general fuente de obligaciones específicas), las medidas de accesibilidad (medidas generales que aparecen cuando el diseño universal no se satisface de manera justificada) y los ajustes razonables

\footnotetext{
2. En este trabajo vamos a referirnos a la asistencia sexual prestada por una persona. No obstante, conviene aclarar que esta asistencia podría llegar a ser prestada por máquinas. Para algunos, esta opción simplifica mucho la discusión, lo que apunta a considerar que uno de los problemas de la asistencia sexual tiene que ver con los derechos y la situación del asistente. Más allá de lo anterior, la posibilidad de usar máquinas en labores como esta también puede plantear problemas (De Asís, 20I 5).

3. "El/la asistente personal es la persona que acompaña a la persona con diversidad funcional para realizar las tareas que esta le indica cuando se le indique, convirtiéndose así en sus brazos, sus ojos, sus oídos, etc.” (Arnau, S., Romañach, J. y Rodríguez-Picavea, A., 2007: 5).
} 
(medidas individuales que surgen cuando la accesibilidad no se satisface a través del diseño o las medidas de manera justificada).

El artículo 9 de la Convención sobre los derechos de las personas con discapacidad (CDPD) se refiere a la accesibilidad universal afirmando: "A fin de que las personas con discapacidad puedan vivir en forma independiente y participar plenamente en todos los aspectos de la vida, los Estados Partes adoptarán medidas pertinentes para asegurar el acceso de las personas con discapacidad, en igualdad de condiciones con las demás, al entorno físico, el transporte, la información y las comunicaciones, incluidos los sistemas y las tecnologías de la información y las comunicaciones, y a otros servicios e instalaciones abiertos al público o de uso público, tanto en zonas urbanas como rurales".

Es posible hablar así de un sentido restringido de accesibilidad y de un sentido amplio. El sentido restringido de la accesibilidad, que se proyecta sobre "productos, entornos, programas y servicios”, supone "el acceso de las personas con discapacidad, en igualdad de condiciones con las demás, al entorno físico, el transporte, la información y las comunicaciones, incluidos los sistemas y las tecnologías de la información y las comunicaciones, y a otros servicios e instalaciones abiertos al público o de uso público, tanto en zonas urbanas como rurales". El sentido amplio de la accesibilidad supone el acceso a todos los bienes y derechos y se fundamenta en la vida independiente, en la participación en la vida social y en la igualdad de oportunidades; conecta con la idea de capacidad, y subraya su dimensión como posibilidad o, si se quiere, como derecho a tener derechos.

Los apoyos y la asistencia son dos herramientas muy relevantes dentro del discurso de los derechos de las personas con discapacidad. Aunque poseen diferentes significados y proyecciones, es común relacionar los apoyos con el ejercicio de los derechos y la asistencia con la vida independiente y con las actividades básicas de la vida diaria.
Así, es posible destacar dos grandes significados de los apoyos. Por un lado, aquel que los conecta con el ejercicio de los derechos, y en este sentido se habla por ejemplo de los apoyos en el ámbito educativo (art. 73 y ss. de la Ley Orgánica 2/2006, de 3 de mayo, de Educación) o del empleo con apoyo (artículo 2.I Real Decreto $870 / 2007$ de 2 de julio). Por otro, el que los relaciona con el ejercicio de la capacidad y, en concreto, con la toma de decisiones (art. I 2 CDPD).

De igual manera podemos referirnos a dos grandes sentidos de asistencia. Por un lado, aquel que en conexión con la vida independiente se proyecta, de nuevo, en el ejercicio de los derechos, identificándose con el primer significado de los apoyos. Por otro, el que vincula asistencia con lo que tradicionalmente se entiende como actividades básicas (o fundamentales) de la vida diaria (art. 2 de la Ley 39/2006 de promoción de la autonomía personal y atención a las personas en situación de dependencia).

De esta forma, apoyos y asistencia pueden ser tratados de manera conjunta poseyendo tres proyecciones: a) la del ejercicio de los derechos; b) la de la toma de decisiones; $y, c)$ la de las actividades básicas (o fundamentales) de la vida diaria.

Pues bien, estas tres proyecciones o significados de los apoyos y la asistencia están presentes en el eje de la accesibilidad y en sus tres grandes momentos. Así, se pueden construir como diseño universal (medidas generales para todos/as, esto es, que posibilitan a todos/as), medidas de accesibilidad (medidas generales que posibilitan a las personas con discapacidad) o como ajustes (medidas individuales).

Si, por ejemplo, tomamos como referencia el derecho de acceso a la justicia, podemos señalar que el diseño universal nos obliga a que los edificios sean accesibles, las medidas a solucionar de manera universal una falta de accesibilidad justificada (por ejemplo, porque el edificio era antiguo) y el ajuste a remediar de manera particular una falta de accesibilidad 
justificada (por ejemplo, acondicionar una determinada sala). Pues bien, este mismo esquema podemos aplicarlo a los apoyos. Estos pueden ser parte del diseño universal o de las medidas (existencia de personal especializado para asistir a personas con discapacidad intelectual en los juzgados), pero también de los ajustes (asistente personal o persona de apoyo para la toma de decisiones).

De la misma manera, apoyos y asistencia, como elementos del eje de la accesibilidad, pueden participar de las distintas construcciones jurídicas que hemos señalado en otros trabajos al referirnos a la accesibilidad. Pueden formar parte del contenido esencial de los derechos y, por tanto, su falta puede suponer una transgresión de ese derecho. Pero también es posible configurarlos como derechos. Así, en Sobre discapacidad y derechos (De Asís, R., 20I3), me he referido a la posibilidad de construir un derecho a los apoyos para la toma de decisiones o un derecho a la asistencia en las actividades fundamentales de la vida diaria.

Ahora bien, como he señalado en otros lugares, el eje de la accesibilidad universal puede verse limitado por tres tipos de circunstancias que pueden ser denominadas como los límites de lo necesario, de lo posible y de lo razonable. Los límites de lo necesario se refieren al tipo de bienes, productos, servicios, derechos sobre los que se proyecta la accesibilidad; los límites de lo posible tienen que ver principalmente con la situación del conocimiento científico y la diversidad humana; los límites de lo razonable se refieren a la ausencia de justificación de la accesibilidad al afectar a otros derechos y bienes o al constituir un coste desproporcionado.

Esta construcción general de los límites del eje de la accesibilidad, adquiere unas connotaciones propias cuando se proyecta en los apoyos y la asistencia. Y ello es así básicamente por dos razones. En primer lugar, porque en ocasiones, en estas situaciones, entran en juego de manera clara los derechos de otra persona (la que realiza el apoyo o la asistencia). En segundo lugar, porque, también en ocasiones, de lo que se trata es de apoyar la voluntad de una persona, y en este punto es posible esgrimir ciertos requisitos justificados en la defensa de la propia persona que se apoya y/o asiste.

En efecto, por mucho que queramos integrar la idea de los apoyos y la asistencia como parte del ejercicio personal de un derecho y como prolongación de la propia persona que lo realiza, la realidad es que, cuando es personal, entran en juego los derechos de esta segunda persona. En este sentido, es necesario realizar un ejercicio de ponderación. Por su parte, cuando el apoyo o la asistencia va dirigido a la toma de decisiones, sobre todo cuando éstas afectan a aspectos personalísimos, suelen aparecer argumentos en la línea de proteger a la propia persona. Qué duda cabe que, en ambos casos, el discurso se complica.

Entre las actividades que se suelen incluir en el ámbito de la asistencia personal están las personales, del hogar, el acompañamiento, la conducción... Sin embargo, no hay consenso en incluir a las actividades sexuales, seguramente por la amplitud del término ${ }^{4}$.

En este sentido, podría decirse que la asistencia sexual en el campo de la discapacidad es un tipo de asistencia especial que incorpora las tres dimensiones de la actividad sexual a los que antes me he referido y añade, además, la preparación para la actividad sexual.

4. Así, Soledad Arnau en un trabajo de $20 I_{3}$ (Arnau, 20I3) diferencia asistencia personal de asistencia sexual. Para Arnau, la asistencia personal es una necesidad de primer orden mientras que la asistencia sexual es una necesidad de segundo orden. Y según esta autora, "la asistencia personal contribuye en alguna medida al ejercicio de la sexualidad, de manera indirecta. Es decir, algunas personas con diversidad funcional, sin sus asistentes personales, no podrían acceder a los recursos existentes actuales (salir para relacionarse, acceder a prostíbulos, sex-shops, preparación para mantener una relación sexual...)". Por su parte la asistencia sexual es un recurso opcional, facilitador, "un recurso directo para que una persona con diversidad funcional pueda vivir su sexualidad, pero nunca debe ser entendida como la única y exclusiva opción posible". Sin embargo, en un trabajo de 2007, que realiza junto a J. Romañach y A. Rodríguez-Picavea (Arnau, S., Romañach, J. y Rodríguez-Picavea, A., 2007: 6), incluyen dentro de lo que llaman como tareas especiales, "las referidas a actividades relacionadas con las relaciones sexuales". Si bien aclaran que se entiende por éstas aquellas que implican el acompañamiento o ayuda en la preparación, con lo que dejan fuera otras que he incluido dentro del término actividades sexuales. 
Me parece importante establecer criterios que nos permitan individualizar la asistencia sexual en el ámbito de la discapacidad, diferenciándola de otros servicios sexuales. Y en este punto, creo que hay dos actividades entre las cuatro señaladas, que adquieren una dimensión propia y que se diferencian de otros trabajos sexuales que trascienden el ámbito de la discapacidad. Ambas adquieren una justificación singular cuando no hay posibilidad material de realizar la acción por parte de la persona que voluntariamente quiere realizarla. Se trata de la preparación para la actividad sexual y de la actividad sexual de una persona sobre su propio cuerpo.

Ahora bien, la primera puede ser considerada como asistencia personal mientras que la segunda sería entonces propiamente la asistencia sexual. Para Antonio Centeno "la asistencia sexual para personas con diversidad funcional es el espacio de intersección de la asistencia personal (materializa el derecho al acceso al propio cuerpo) y del trabajo sexual (se obtiene placer sexual a cambio de dinero)" (Centeno, 20I4). Para este autor, la asistencia sexual tiene que ver con la autosexualidad y es que la asistencia que supone práctica sexual es, para él, prostitución.

\section{La asistencia sexual como derecho}

Una vez determinado el sentido de la asistencia sexual, podemos volver al análisis sobre la posibilidad de configurarla como derecho.

Pues bien, como vimos uno de los caminos posibles consistía en considerar la asistencia como fruto de una relación jurídica, en la que un sujeto estuviera en una situación de derecho y otro en una de obligación. Como es sabido, el artículo ro89 del Código Civil establece que las obligaciones nacen de la Ley, de los contratos y de los cuasicontratos. De esta forma, sería algo así como considerar la asistencia sexual como un servicio.

Para seguir esta vía, hay que superar el requisito de la validez, esto es, tener en cuenta lo que nos dice el artículo I 255 del Código Civil: "Los contratantes pueden establecer los pactos, cláusulas y condiciones que tengan por conveniente, siempre que no sean contrarios a las leyes, a la moral ni al orden público".

¿Es la asistencia sexual contraria al ordenamiento jurídico? Como es sabido, el Derecho español es algo tibio en la regulación del trabajo sexual. En este sentido, podemos afirmar que no existe la prohibición del ejercicio libre del trabajo sexuals. Y si eso es así, la asistencia personal no está prohibida.

Como he recalcado, la admisión del trabajo sexual radica en su ejercicio libre y este es, como es sabido, el punto más conflictivo de esta problemática, y al que se unen otras consideraciones como la explotación de la mujer o la cosificación de las personas. Sin embargo, estos argumentos pierden fuerza con la configuración que hemos realizado de la asistencia personal que, con ese significado, puede ser el objeto de un contrato en el que se establezca derechos y obligaciones.

Si la asistencia sexual, concebida tal y como hemos hecho, puede ser construida como objeto de un servicio, ¿por qué interesa configurarla como un derecho moral o como un derecho humano? Pues considero que son dos las razones. La primera tiene que ver con su fuerza y su coste; la consideración de la asistencia sexual como un derecho con una fuerte justificación ética o como un derecho humano, aporta razones para implicar al Estado en su satisfacción. La segunda, tiene que ver con presentarlo como una demanda coherente con el movimiento que lucha contra la discriminación y por los derechos de las personas con discapacidad.

\footnotetext{
5. Suele citarse para apoyar esta conclusión en España el célebre caso de la magistrada Gloria Poyatos, que se dio de alta en Hacienda y Seguridad Social como prostituta. En nuestro ordenamiento jurídico el art. I87 del Código Penal se refiere al delito de prostitución forzada, que en virtud del art. I 88 del mismo cuerpo legal, se agrava si es un menor o una persona con discapacidad que necesita especial protección. Por su parte, la Ley de Seguridad Ciudadana castiga la prostitución cuando se realiza en determinados lugares públicos. Además, diversas ordenanzas municipales se refieren a la prostitución.
} 
Como hemos visto, la consideración de la asistencia sexual como derecho requiere de una razón jurídica (básicamente una norma en sentido amplio) y de una razón ética. Veamos qué caminos tenemos para encontrarlo.

La razón jurídica puede venir de la conexión entre la actividad sexual y los derechos sexuales o bien de la conexión entre la actividad sexual y otros derechos humanos.

Los derechos sexuales fueron definidos por primera vez, en un contexto de derechos humanos, en la Cuarta Conferencia Mundial de la Mujer: "Los derechos humanos de la mujer incluyen su derecho a tener control sobre las cuestiones relativas a su sexualidad, incluida su salud sexual y reproductiva, y decidir libremente respecto de esas cuestiones, sin verse sujeta a la coerción, la discriminación y la violencia. Las relaciones igualitarias entre la mujer y el hombre respecto de las relaciones sexuales y la reproducción, incluido el pleno respeto de la integridad de la persona, exigen el respeto y el consentimiento recíprocos y la voluntad de asumir conjuntamente la responsabilidad de las consecuencias del comportamiento sexual" (Declaración de Beijing y Plataforma de Acción, Cuarta Conferencia Mundial sobre la Mujer, I 5 de Septiembre I995).

Entendemos por derechos sexuales un conjunto de pretensiones que tienen como principal misión garantizar el control autónomo y responsable sobre todas las cuestiones relativas a la sexualidad. Por su parte, los derechos reproductivos protegen la toma de decisiones sobre la posibilidad de procrear o no.

Se trata de derechos que se fundamentan en los derechos humanos (Declaración de los Derechos Sexuales de la Asociación Mundial para la Salud Sexual) y en este sentido, se apoyan en los valores que presiden el discurso de éstos (dignidad, libertad, igualdad) y, también, se relacionan estrechamente con muchos de los bienes que están detrás de ellos (como por ejemplo, la salud).

En todo caso, no hay claridad sobre el alcance y el contenido de estos derechos. Dentro de los derechos sexuales es posible identificar diferentes proyecciones. Así, entre los derechos sexuales cabe citar, la libertad sexual (autonomía en la toma de decisiones sobre la vida sexual), la privacidad, la no discriminación y la educación, información y salud sexual. Por su parte, forman parte de los derechos reproductivos la libertad reproductiva (autonomía en la toma de decisiones reproductivas) y la salud reproductiva. En este sentido, se trata de derechos que demandan no sólo protección sino también prestación.

El impulso de los derechos sexuales se ha producido en el marco de la reivindicación de los derechos de las mujeres y de la lucha contra la discriminación en la que éstas se encuentran (Londoño, I996).

La incursión de la discapacidad en el discurso de los derechos exige la extensión de los derechos sexuales y reproductivos a las personas con discapacidad. Ciertamente no se trata de un tema novedoso. Como es sabido, en el año I98I, en La Habana, se adoptó la llamada Carta de Derechos Sexuales en favor de las personas con discapacidad, promovida por el movimiento asociativo cubano. En dicha carta se proclamaban los siguientes derechos: (i) el derecho a la expresión sexual, (ii) el derecho a la intimidad; (iii) el derecho a ser informado; (iv) el derecho a tener acceso a los servicios necesarios, como son el asesoramiento sobre anticoncepción, atención médica y asesoramiento genético y sobre sexualidad; (v) el derecho a escoger el estado civil que más convenga a la persona con discapacidad; (vi) el derecho a tener o no una prole; (vii) el derecho a tomar las decisiones que afectan la vida de cada uno; (viii) el derecho a intentar el desarrollo de todo el potencial del individuo.

No obstante, se trata de una cuestión que todavía no ha sido objeto de atención desde el enfoque de los derechos. Y no lo ha sido por la visión socialmente mayoritaria de la discapacidad y, también, por lo que supone el tratamiento de las cuestiones relacionadas con la sexualidad.

Y estos mismos condicionantes los encontramos si queremos llevar nuestra argumentación por la 
vía de la incursión de la actividad sexual en el contenido de otros derechos, como la libertad o la salud, o en otros bienes. Con independencia de que luego vuelva sobre ese punto, conviene advertir que esta incursión no es unánimemente aceptada y que, en el campo jurídico, el reconocimiento de derechos implícitos resulta problemático en algunos contextos.

Como es sabido, se habla de derechos implícitos para hacer referencia tanto a derechos no expresamente recogidos en una constitución y, en línea de principio, con un contenido diferente a los sí enumerados; cuanto a derechos cuyo contenido se deduce de los enumerados (Gros Espiell, 2000: I46). La Constitución española no se refiere a los derechos implícitos (como sí lo hace, por ejemplo, la Constitución argentina, en su artículo 33. Ahora bien, no es extraño encontrar argumentaciones que deducen derechos y exigencias del marco de valores constitucionales o que se refieren a bienes y principios constitucionales no expresamente aludidos en el texto ${ }^{6}$.

En todo caso, el éxito de la línea argumentativa anterior creo que está estrechamente relacionado con la existencia o no de un argumento ético convincente. Pues bien, para justificar la actividad sexual como razón ética se nos presentan, de nuevo, dos caminos: el de las necesidades o el de entenderla como un bien o actividad fundamental.

En el discurso contemporáneo de los derechos, es habitual referirse a las necesidades básicas como referentes justificatorios (Añon Roig, I994). Y esto ocurre también en buena parte de la literatura de la filosofía moral, donde la satisfacción de las necesidades básicas constituye un imperativo ético (Ribotta, 20I I: 259 y ss.). Ahora bien, conviene advertir que no todo derecho pretende satisfacer una necesidad básica y que, por tanto, la consideración o no de la actividad sexual como necesidad básica no nos

6. En España suele citarse como ejemplo la Sentencia 3I/I98 I del Tribunal Constitucional que deduce el principio in dubio pro reo de la presunción de inocencia contenida en el artículo 24 (deducción muy cuestionada doctrinalmente). resolvería el problema, aunque sí que afianzaría la posibilidad de entender la asistencia sexual como derecho.

El problema presente en el discurso sobre las necesidades es que no existe un acuerdo sobre éstas ni sobre su distinción con los satisfactores, los deseos o los gustos (Ribotta, 2008: 29 y ss.). $\mathrm{Y}$ en este punto, tampoco hay un consenso sobre si la actividad sexual puede ser considerada como una necesidad. Así, para aquellos que manejan una concepción de las necesidades básicas que implica considerar como tales exclusivamente a aquellas cuya insatisfacción produce la muerte, la actividad sexual no es una necesidad básica. Sin embargo, está presente en algunas de las tipologías de las necesidades (Braybrooke, I987: 60 y ss.).

Por otro lado, en el discurso de la terapia ocupacional, con una importante proyección en el campo de la asistencia personal, se utiliza el término de "Actividades Básicas de la Vida Diaria” para hacer referencia a aquellas actividades orientadas al cuidado del propio cuerpo y también a las actividades fundamentales para vivir en un mundo social (Rogers y Holm, 2009: I 8 I y ss.; Christiansen y Hammecker, 2009: I 55 y ss). Pues bien, en el catálogo de estas actividades más utilizado, el de la Asociación Americana de Terapeutas Ocupacionales, la actividad sexual aparece reconocida como Actividad Básica de la Vida Diaria (American Occupational Therapy Association, 20I4).

De esta forma, la justificación de la asistencia sexual en relación con personas que no pueden realizar actividad sexual sobre su propio cuerpo puede encontrar una justificación ética de la mano de la teoría de las necesidades o de la mano de las Actividades Básicas de la Vida Diaria $^{7}$, e igualmente puede formar parte de los derechos sexuales o del derecho a elegir una

7. En apoyo a esta razón estaría el plantearse la posibilidad de prohibir la actividad sexual de una persona sobre su propio cuerpo. Más allá de que puedan existir planteamientos de corte ético y religioso (e incluso con apariencia médica) que defiendan esa posibilidad, no parece que el Derecho pudiera hacerlo. 
forma de vida (dada la conexión existente entre las Actividades Básica de la Vida Diaria y este derecho) (De Asís, 20I3: 9I y ss.).

Si esto es así, podríamos referirnos a ella en términos de derecho e, incluso, desde la manera en la que hemos configurado los apoyos y la asistencia, considerar que forma parte del contenido esencial de los derechos (de la libertad sexual o del derecho a elegir una forma de vida).

Ahora bien, como derecho y como bien éticamente relevante, posee limitaciones en su propia construcción, que tienen que ver con la situación correlativa de obligación y, por tanto, con el papel del Estado y con los derechos de la persona que realiza la asistencia.

$¿$ Es posible afirmar que, como tengo derecho a la asistencia sexual, el Estado debe proporcionarme ayuda en este campo? Cuando me referí al eje de la accesibilidad señalé cómo uno de los límites venía de la mano de la razonabilidad y que ésta, en muchas ocasiones, se traducía en una cuestión de índole económica. Ahora bien, si situamos a la asistencia sexual en el campo de los derechos humanos, esta cuestión pierde fuerza. Como he señalado en otros lugares: "Limitar un derecho por su coste excesivo no es un argumento que pueda tener cabida en el discurso de los derechos, salvo que se demuestre que dicho coste daña de manera insoportable otros derechos. Y en este punto lo relevante no es el coste en sí sino la afectación al derecho. La economía es un instrumento que, como tal, debe estar al servicio de los derechos y no éstos al servicio de la economía” (De Asís, 2or6: 65). Así, “el coste como argumento independiente del disfrute de los derechos no puede tener cabida aquí. Su uso, como argumento admisible en el discurso de los derechos, requiere de su conexión con estos (en el sentido de expresar una limitación de los derechos de otros). Pero, además, deberá evaluar el coste que conlleva la insatisfacción del bien en términos de falta de inclusión o de segregación” (De Asís, 20I3: I 24).

De esta manera, existen argumentos para defender una actuación prestacional por parte del Estado que tendrá que ponderarse con su afectación a otros derechos y bienes fundamentales (como es habitual en el discurso de los derechos).

Y algo parecido ocurre con la otra situación de obligación presente en la construcción de este posible derecho: la del asistente. En este sentido, la construcción de este derecho requiere establecer de manera clara el alcance de la asistencia y los derechos y obligaciones del asistente. Se trata de una cuestión que no es posible abordar aquí en su complejidad. No debemos perder de vista que la definición de los derechos y las obligaciones de la asistencia personal es, todavía, una cuestión pendiente de resolver de manera normativa. Esta ausencia de regulación complica aún más la cuestión de la asistencia sexual. En este sentido, los derechos y obligaciones del asistente suelen estipularse en un contrato que debe ajustarse al marco legislativo laboral y, obviamente, respetar los derechos del asistente ${ }^{8}$.

Y tampoco puedo detenerme en la proyección de este posible derecho en relación con personas con discapacidad intelectual y con personas con discapacidad psicosocial. En estos casos, existe un doble apoyo o asistencia, por un lado, la asistencia sexual estudiada, por otro, la que tiene que ver con la decisión de realizar o no una actividad sexual. Esta segunda consiste en un apoyo a la toma de decisiones, similar a cualquier otro (Cuenca, 20I2; Bariffi, 20I4). Eso sí, el apoyo no puede ser realizado por el asistente sexual, siempre que medie una contraprestación económica especial por este servicio.

8. En España el contrato del asistente es, a veces, construido equiparándolo al servicio doméstico o al cuidador de residencia, sin que pueda equipararse a ninguna de estas dos figuras. En la legislación comparada donde se recoge la figura de la asistencia personal, se aluden entre otros, a los siguientes derechos: no discriminación, salario mínimo, horario laboral, descansos, vacaciones, permisos... 
Referencias bibliográficas

American Occupational Therapy Association (20I4): "Occupational therapy practice framework: domain and process" ( $3 \mathrm{rd}$ ed.), American Journal of Occupational Therapy, 68: I-48.

Añon, M.J. (I994): Necesidades y derechos: un ensayo de fundamentación, Madrid: Centro de Estudios Constitucionales.

Arnau, S. (2013): Asistencia Sexual. Otro medio, no un fin, para alcanzar el Derecho Humano a una Vida Independiente en materia de Sexualidad (en línea).

$<$ http://www.slideshare.net/solearnau/asistenciasexual-sept-20I3 $3>$, acceso I 5 de septiembre de 2016.

Arnau, S. (20I4): "La asistencia sexual a debate". Dilemata, I 5: 7-I4.

Arnau, S., Romañach, J. y Rodríguez-Picavea, A. (2007): Asistencia personal para la vida independiente y promoción de la autonomía de las personas con diversidad funcional (discapacidad) en España, Madrid: Departamento de Filosofía y Filosofía Moral y Política (UNED) y Foro de Vida Independiente.

Bariffi, F.J. (20I4): El régimen jurídico internacional de la capacidad jurídica de las personas con discapacidad, Madrid: Cinca.

Barranco, M.C. (2016): Condición humana y derechos humanos: algunas claves filosóficas para un modelo de derechos humanos, Madrid: Dykinson.

Braybrooke, D. (1987): Meeting Needs, New Jersey: Princeton University Press.

Centeno, A. (20I4): Asistencia sexual para personas con diversidad funcional (en línea).

$<$ http://derechoshumanosya.org/asistencia-sexualpara-personas-con-diversidad-funcional/>, acceso I 2 de septiembre de 2016 .

Cuenca, P. (2OI2): "El sistema de apoyo en la toma de decisiones desde la Convención Internacional sobre los Derechos de las Personas con
Discapacidad: principios generales, aspectos centrales e implementación en la legislación española”, REDUR, IO: 6I-94.

Christiansen, C. H. y Hammecker, C. L. (2009): "Self care", en Bonder, B.R. y Wagner, M.B. (eds.): Functional performance in older adults, Philadelphia: F.A. Davis.

De Asís, R. (200I): Sobre el concepto y el fundamento de los derechos: una aproximación dualista, Madrid: Dykinson.

De Asís, R. (2013): Sobre discapacidad y derechos, Madrid: Dykinson.

De Asís, R. (2015): Una mirada a la robótica desde los derechos humanos, Madrid: Dykinson.

De Asís, R. (20I6): "El eje de la accesibilidad y sus límites", Anales de Derecho y Discapacidad, I: $5 \mathrm{I}-67$.

Declaración de Beijing y Plataforma de Acción, Cuarta Conferencia Mundial sobre la Mujer, I 5 de Septiembre 1995 (en línea). http://www.un.org/womenwatch/daw/beijing/ pdf/BDPfA \% 2oS.pdf, acceso I 2 de diciembre de 2017.

España. Ley 39/2006 de promoción de la autonomía personal y atención a las personas en situación de dependencia, Boletín Oficial del Estado, I 5 de diciembre de 2006, núm. 299, pp. 44I 42-44I 56.

España. Ley Orgánica 2/2006, de 3 de mayo, de Educación, Boletín Oficial del Estado, 4 de mayo de 2006, núm. I06, pp. I7I 58-I7207.

España. Real Decreto 870/2007, de 2 de julio, por el que se regula el programa de empleo con apoyo como medida de fomento de empleo de personas con discapacidad en el mercado ordinario de trabajo, Boletín Oficial del Estado, I4 de julio de 2007, núm. I68, pp. 30618-30622.

Gros Espiell, H. (2000): "Los derechos humanos no enunciados o no enumerados en el Constitucionalismo Americano y en el artículo 
29.C de la Convención Americana sobre Derechos Humanos", Anuario Iberoamericano de Justicia Constitucional, 4: I45-172.

Hohfeld, W.N. (1968): Conceptos jurídicos fundamentales, trad. de G. R. Carrió, Buenos Aires: Centro Editor de América Latina S.A.

Londoño, M.L. (I996): Derechos sexuales y reproductivos, Colombia: ISEDER.

Nino, C.S. (I990): "Sobre los derechos morales", Doxa, 7: 3II-325.

Organización de las Naciones Unidas, ONU (2006). Convención Internacional sobre los Derechos de las Personas con Discapacidad, Nueva York: ONU.

Palacios, A. (2008): El modelo social de la discapacidad, Madrid: CERMI.

Ribotta, S. (2008): "Necesidades y derechos: un debate no zanjado sobre fundamentación de derechos", Jurídicas, 5 (I): 29-56.
Ribotta, S. (20I I): "Necesidades, igualdad y justicia. Construyendo una propuesta igualitaria de necesidades básicas", Derechos y Libertades, 24: 259-299.

Rodríguez Toubes, J. (I995): La razón de los derechos, Madrid: Tecnos.

Rogers, J. C. y Holm, M. B. (2009): “Assessment of self-care”, en Bonder, B.R. y Wagner, M.B. (eds.): Functional performance in older adults, Philadelphia: F.A. Davis.

World Association for Sexual Health (20I4): Declaración de los Derechos Sexuales (en línea). <http://www.worldsexology.org/ wp-content/uploads/20I3/o8/declaracion_ derechos_sexuales_sepo3_20I4.pdf >, acceso I 2 de diciembre de 2017. 